\title{
A Reliable Modular Based PV-Battery Hybrid System with Peak Shaving Capability
}

\author{
Umer Sohail, Student Member, IEEE, Hamed Nademi*, Senior Member, IEEE, and Lars Einar Norum, Member, IEEE
}

Department of Electrical Engineering, UiT The Arctic University of Norway, 8514, Narvik, Norway

*ABB, Industrial Automation Division, 0603, Oslo, Norway

\begin{abstract}
The driving factors in emerging photovoltaic (PV) systems and battery-energy-storage systems (BESS) are highly scalable feature, modular and flexible structures with superior transformerless performance. The feasibility of Modular Multilevel Converter (MMC) to operate without overall DC-link allows the integration of PV generators and battery strings with its submodules (SMs), whereas each SM acts as an independent voltage source due to its ability to insert/bypass the isolated DClink capacitor. In this paper, MMC topology based-split BESS along with distributed PV generators, integrated into each $S M$ is proposed. The presented flexible energy conversion system extracts the maximum power from all distributed PV generators under substantial partial shading and allows the peak shaving to match the intermittent $P V$ power with the variable power demand from the smart grid. With the absence of common DC-link and presence of large arm power variations, the introduced distributed PV-battery system provides balanced three-phase sinusoidal currents to the grid. A five-level three-phase MMC with proposed distributed PV-battery hybrid topology is developed. The simulation results under fast variations in solar irradiance and power demand by the grid are included, which demonstrate its superior performance.
\end{abstract}

Keywords-PV-battery, hyrbid system, Split battery, Distributed PV generators, Modular Multilevel Converter (MMC), Peak shaving, Partial Shading, Maximum Power Point Tracking (MPPT), Flexible energy conversion system, autonomous control

\section{INTRODUCTION}

Continuously growing energy demand, depletion, and adverse effects of conventional electric power sources, e.g., fossil fuels have demanded for sustainable solutions to overcome these issues. However, increasing grid integration of renewable energy sources, like PV plants, is posing several stability issues due to intermittent power generation. Partial shading is another important aspect of PV systems i.e. shaded PV modules also negatively affect the generation of unshaded PV modules. The centralized MMC-based PV plant proposed in $[1,2]$ deploys single boost converter for tracking maximum power point and reducing the cost, however the central PV systems are susceptible to problems caused by partial shading or mismatch among PV generators.

Energy storage is a promising way to deal with intermittent power generation. One of the solutions for reliable energy storage system is the use of short battery strings, which causes mitigation of issues like overcharging, overheating or shutdown due to damage in single battery cell [3]. The first

field application of a dynamic energy storage device was installed on power distribution network of $11 \mathrm{kV}$ with significant penetration of wind power in the UK by ABB [4].
Larger battery strings can be integrated into the grid without the use of any DC-DC converter, but it requires relatively complex and costly battery management system. The long string batteries have problem of storage capacity with failure in one cell. As reported in [3], the solution to overcome this issue has proposed the use of shorter battery strings. Alternative approach is through MMC, which suites better in combination with modular battery banks consisting of shorter strings of the battery cells.

The applicability of MMC topology for battery energy storage has been evaluated by numerous researchers like $[5,6]$. Although, it is shown that more semiconductor devices than conventional multilevel converters are required in the MMC with distributed battery energy-storage, but this proposal provides highly efficient, reliable, and versatile solution for energy-storage integration. A hybrid battery and ultra-capacitor energy-storage system based on the MMC was proposed in [7]. The direct conversion of DC-AC was realized with the MMC and inductor of the MMC circuit was eliminated which resulted in shrinking of capacitor size. These benefits were reached at the cost of use of more switching elements. Detailed study of centralized energy storage systems was carried out and three major categories of existing systems were identified in [8]. These systems included high-voltage batteries with Neutralpoint-clamped converter and cascaded H-bridge converter based low-voltage modular batteries. Furthermore, this proposal suffers from considerable effect of parasitic capacitances which influenced the output mainly during switching state transition. PV-battery system with reconfigurable structure introduced in [9] comprises of single stage power conversion. The reconfigurable solar converter with Lithium-Ion battery takes advantage of reduced number of conversion stages, which not only reduces complexity but also benefits in terms of cost, volume and weight. In [10], the extension of a MMC is demonstrated to form a three-port converter including AC grid, DC grid and the batteries as storing elements. The fault tolerance feature of this configuration is also established to cope with both the DC and AC grid faults. Based on aforementioned discussion, the MMC with integrated battery is found to be the most proficient solution for modern energy storage requirements and works for both AC and DC grids. In this study, a MMC based multistring PV system is proposed to eliminate the adverse impacts of partial shading and parameters mismatch which enables the tracking of MPP of individual PV generator under heavily shaded conditions. With arrangement of individual DC-DC 
converter as an interface between SM and solar array, a highly scalable topology is achieved to enable transformerless operation in high-voltage grid applications.

An improvement on stability and other issues due to intermittent nature of $\mathrm{PV}$ is also considered. The proposed configuration not only offers the peak shaving and spinning reserve to follow the variable power demand, but also brings flexibility and reliability into the overall system. The operation of the proposed system is verified through simulations for different case studies and results prove its feasibility for the grid-connected PV plants. Phase-disposition pulse width modulation (PDPWM) technique is utilized for generating the switching patterns of the MMC. Averaging control together with individual balancing algorithm is implemented to balance the SM capacitor voltages under different operating conditions. Phase current control method is used to suppress the circulating currents between three phases of grid-connected MMC.

The designed topology has a fault-ride-through capability i.e. the system keeps on working with same performance when fault occurs on a PV generator, since dedicated battery overtakes its PV generator. The simulation analysis shows the effectiveness and validity of the control strategy.

\section{Mathematical Modeling OF A Modular PV- BATTERY CONFIGURATION}

\section{A. Mathematical Model of a MMC}

The schematic diagram of three-phase MMC is given in Fig. 1. The mathematical model of the MMC given below is described in accordance with this diagram. In the mathematical model, $V_{u p j}$ and $V_{\text {lowj }}$ represent the upper and lower arm voltages of $j^{\text {th }}$ phase respectively $(j=a, b, c) ; i_{j}$ defines the $\mathrm{AC}$ phase current of $j^{\text {th }}$ phase; $\mathrm{R}_{0}$ and $\mathrm{L}_{0}$ are the resistance and inductance of arm; $V_{j}$ is the fundamental phase voltage; $i_{u p j}$ and $i_{\text {lowj }}$ indicate the upper arm current and lower arm current of $j^{\text {th }}$ phase.

$$
\begin{aligned}
& V_{j}=\frac{1}{2}\left(V_{l o w_{j}}-V_{u_{j}}\right)+\frac{1}{2} R_{0} i_{j}+\frac{1}{2} L_{0} \frac{d i_{j}}{d t} \\
& i_{j}=i_{u p_{j}}-i_{l_{l o w}} ; i_{\text {cir }_{j}}=0.5\left(i_{u_{j}}+i_{\text {low }_{j}}\right)
\end{aligned}
$$

\section{B. Proposed Structure of the Modular-based PV-Battery System and Control Principles}

Several stability issues arise on point of common coupling (PCC) with the increase in PV penetration when there is less load and more PV generation and vice versa. BESS eliminate the effects of intermittent power generation of PV system and increases the flexibility of the system. The proposed topology, shown in Fig. 1 and Fig. 2, integrates both PV and battery modules with SMs of the MMC. It consists of following modules: a) Power module consists of a PV string, Perturb and Observe (P\&O) MPPT technique and DC-DC buck converter; b) Switching Module is MMC half-bridge SM and PD-PWM along with sorting algorithm and overall SM capacitor voltage control is used for switching of power switches of SM; and c) Backup module is composed of a battery, and a non-isolated bidirectional DC-DC converter having $1 \mathrm{mH}$ inductor, which not only allows the battery to charge and discharge to reduce intermittency of PV generators; but also avoids the AC and higher order harmonics from entering the battery. During continuous operation mode of converter, $\mathrm{S}_{\mathrm{b} 2}$ will act as a diode when $S_{\mathrm{b} 1}$ will be active for PWM and it will result in step-down in the voltage (buck mode) or charging battery. In contrast, battery will operate in discharge mode [11]. The control system bypasses the split batteries by turning off both switches $\left(\mathrm{S}_{\mathrm{b} 1}\right.$ and $\mathrm{S}_{\mathrm{b} 2}$ ) of their DC-DC converters when PV power meets the power demand by the load or grid. The explicit form of equations of charging and discharging modes for the utilized Lithium-Ion battery given in [12] is followed here.

\section{B1. Overall Control of SM Capacitor Voltage}

Arm currents can also be written in terms of voltage drop across arm inductor $\left(L_{o}\right)$, as shown in (3).

$$
\mathrm{i}_{\mathrm{up}_{\mathrm{j}}}=\frac{1}{\mathrm{~L}_{\mathrm{o}}} * \int\left(\mathrm{V}_{\mathrm{DC}+}-\sum\left(\mathrm{N}_{\mathrm{i}} * \mathrm{~V}_{\mathrm{c}-\mathrm{i}}\right)-\mathrm{V}_{\mathrm{j}} \quad \begin{array}{l}
\text { where } \mathrm{j}=\mathrm{a}, \mathrm{b}, \mathrm{c} ; \\
\mathrm{i}=1<=\mathrm{N} ;
\end{array}\right.
$$

The submodule capacitor voltage can be written in terms of arm currents, as in (4).

$$
\left.\mathrm{V}_{\mathrm{c}-\mathrm{i}}=\frac{1}{\mathrm{C}_{\mathrm{SM}}} * \int \mathrm{i}_{\text {up } / \text { low }_{\mathrm{j}}} * \mathrm{~N}_{\mathrm{i}}\right) \quad \begin{aligned}
& \text { where } \mathrm{j}=\mathrm{a}, \mathrm{b}, \mathrm{c} ; \\
& \mathrm{i}=1<=\mathrm{N} ;
\end{aligned}
$$

$N_{i}$ is the gating signal from the control system to regulate submodule capacitor voltage and arm current. An increase in $N_{i}$ will result in decrease in arm current if submodule capacitor voltage will be kept constant as shown by (3), and an increase in submodule capacitor voltage if arm current will be kept constant as shown by (4).

The energy stored in the submodule capacitor is the controlling factor for the capacitor voltage, to control the SM capacitor voltage of a phase, the implemented control system controls the reference power of that phase. In the proposed system, if the average SM capacitor voltage exceeds than the reference, the control system generates a positive reference for that phase which will increase its power reference to reduce the energy and voltage, contrarily it does vice versa.

\section{B2. Phase Current Control}

When upper and lower arm AC currents are equal $\left(i_{\text {upacj }}=\right.$ $\left.\mathrm{i}_{\text {lowacj }}\right)$, and the zero-sequence current component is zero $\left(i_{u p 0 j}=\right.$ $i_{\text {low } 0 j}=0$ ), the DC-current in each phase can be calculated by using (5). To have equal dc components of arm currents among the three phases, and to eliminate the circulating currents $\left(i_{c i r}\right)$, the arm currents should respect (6).

$$
i_{d c_{j}}=\frac{i_{u_{j}}+i_{\text {low }_{j}}}{2}-i_{\text {cir }_{j}} \quad \text { where } j=a, b, c ;
$$

Therefore, to eliminate the circulating current, the following equation should be realized:

$$
i_{d c_{j}}=\frac{i_{u p_{j}}+i_{\text {low }_{j}}}{2} \quad \text { where } j=a, b, c ;
$$




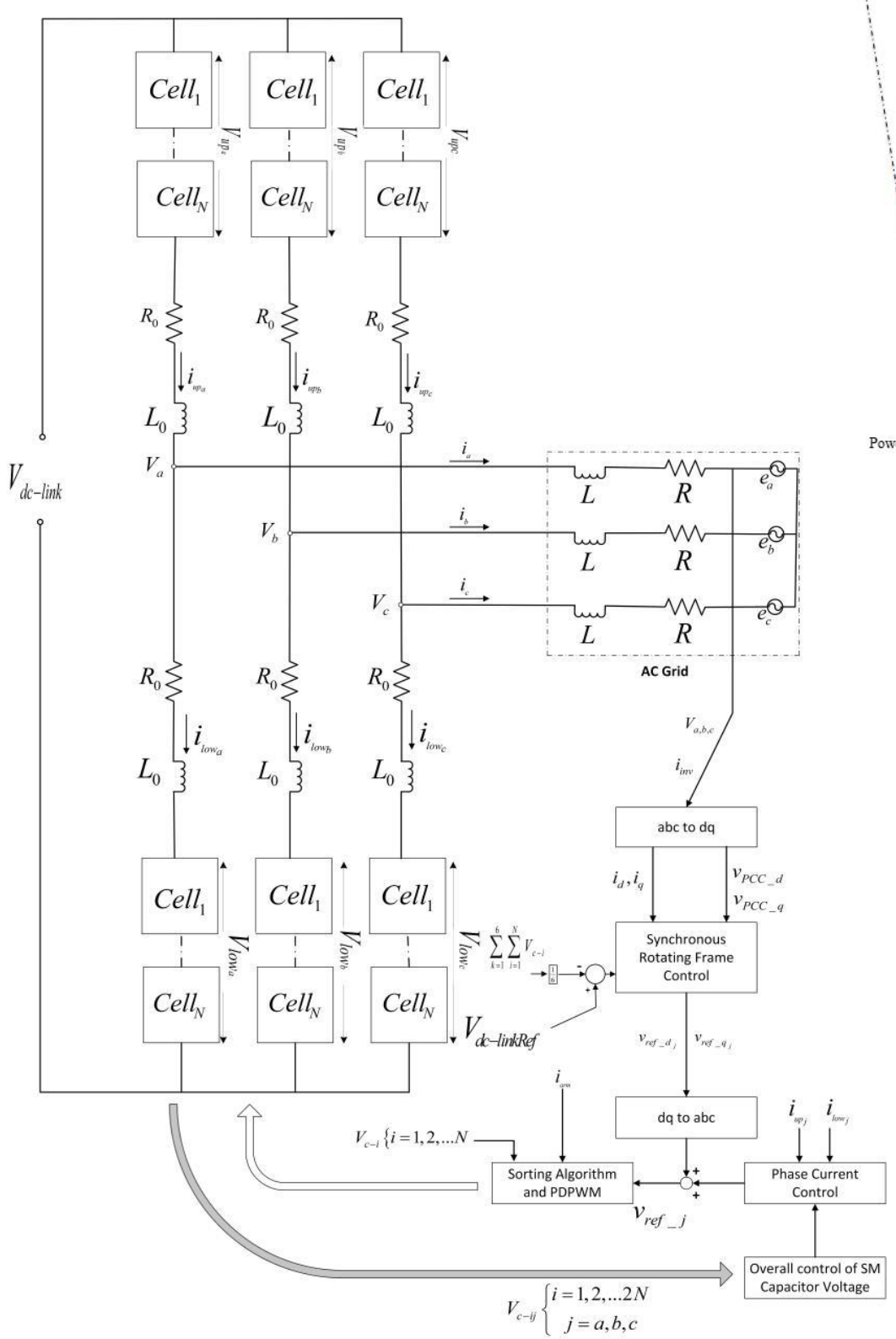

Fig. 1. Overall designed PV-battery system with different control blocks.

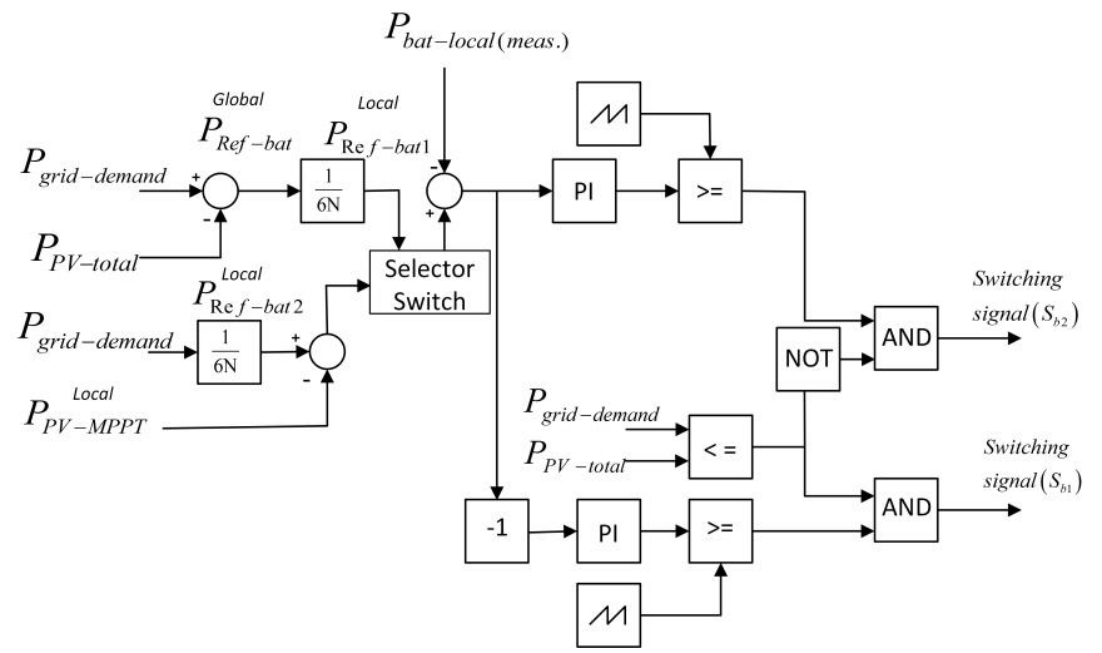

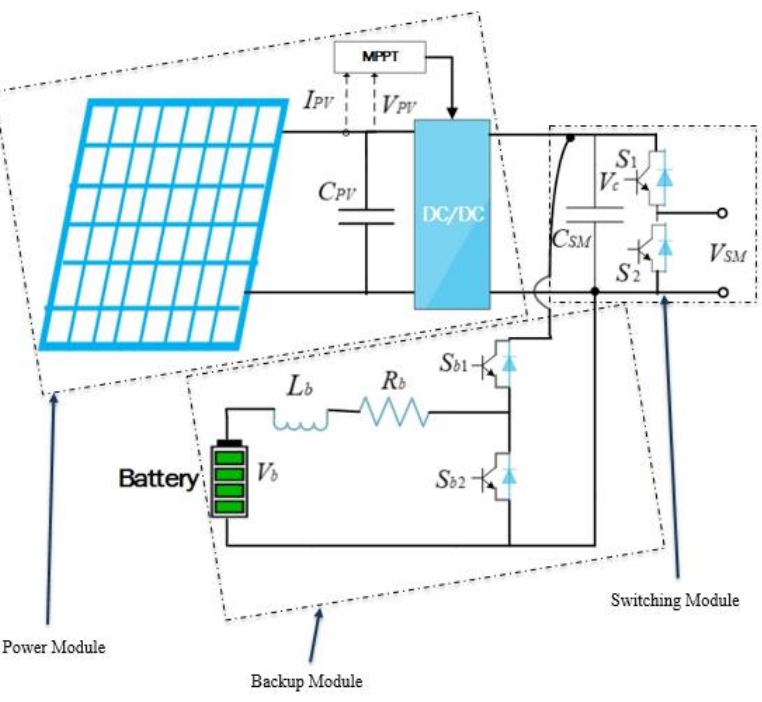

Fig. 2. Schematics of the proposed topology.

TABLE I. TITAN S6-60-2-240 PV MODULE AND BUCK CONVERTER PARAMETERS

\begin{tabular}{|l|l|}
\hline Parameter & Value \\
\hline Nominal Power $\left(P_{M P P}\right)$ & $238.82 \mathrm{~W}$ \\
\hline MPP Voltage $\left(V_{M P P}\right)$ & $29.63 \mathrm{~V}$ \\
\hline MPP Current $\left(I_{M P P}\right)$ & $8.06 \mathrm{~A}$ \\
\hline Open Circuit Voltage $\left(V_{O C}\right)$ & $37.27 \mathrm{~V}$ \\
\hline Short Circuit Current $\left(I_{S C}\right)$ & $8.49 \mathrm{~A}$ \\
\hline CPV & $1200 \mu \mathrm{F}$ \\
\hline L $_{\text {buck }}$ & $402 \mu \mathrm{H}$ \\
\hline Cout $_{\text {oC }}$ SM & $20.402 \mathrm{mF}$ \\
\hline Rbuck_inductor & $0.1 \Omega$ \\
\hline
\end{tabular}

TABLE II. PARAMETERS OF THE BACKUP MODULE

\begin{tabular}{|l|l|}
\hline Parameter & Value \\
\hline Storage Capacity of a Split Battery & $6.6 \mathrm{Ah}$ \\
\hline Nominal Voltage of a Split Battery & $100 \mathrm{~V}$ \\
\hline Initial SOC & $70 \%$ \\
\hline Inductance of DC-DC Converter & $1 \mathrm{mH}$ \\
\hline Battery Response Time & $0.001 \mathrm{~s}$ \\
\hline Proportional Gain & 1.5 \\
\hline Integral Gain & 6.5 \\
\hline
\end{tabular}

TABLE III. PARAMETERS OF THE SIMULATED MMC SYSTEM

\begin{tabular}{|l|l|}
\hline Parameter & Value \\
\hline Switching Frequency & $2 \mathrm{kHz}$ \\
\hline Fundamental Frequency & $50 \mathrm{~Hz}$ \\
\hline Grid Phase Voltage $($ RMS $)$ & $400 \mathrm{~V}$ \\
\hline Line Inductance $(L)$ & $5 \mathrm{mH}$ \\
\hline Line Resistance $(R)$ & $1 \mu \Omega$ \\
\hline Arm Inductance $\left(L_{0}\right)$ & $1 \mathrm{mH}$ \\
\hline Arm Resistance $\left(R_{0}\right)$ & $1 \mathrm{~m} \Omega$ \\
\hline SM Capacitance $\left(C_{S M}\right)$ & $20 \mathrm{mF}$ \\
\hline DC-Link Voltage & $800 \mathrm{~V}$ \\
\hline
\end{tabular}

Fig. 3. Controller for split battery energy storage system (BESS). 


\section{B3. Control System for Solution with Split Battery}

The control system for the SM-integrated split batteries, shown in Fig. 3, is responsible for the charging and discharging of the batteries. It takes power demand from the smart grid and based on the mismatch between the instantaneous power generation of the distributed PV generator, it calculates the global power reference for the overall BESS. It's other mode of operation is peak shaving within a SM, for which control system calculates a local power reference for the a split battery. Based on the realtime power measurement from each split battery, the propotional-integral (PI) based linear control system controls the switching the of non-isolated DC-DC converters and tries to make the mismatch equal to zero.

\section{B4. Active and Reactive Power Control}

MMC is acting as an interface between PV-Battery and smart grid. Inductors $(L)$ are used to link the MMC with the grid. The real and reactive power exchange between the MMC based PV-Battery and grid can be expressed as done in (7) and (8):

$$
\begin{array}{cc}
P=\frac{V_{P C C} * V_{j}}{X_{0}+X} \sin \delta & \text { where } j=a, b, c ; \\
Q=\frac{V_{j} * \cos \delta-V_{P C C}}{X_{0}+X} V_{P C C} & \text { where } j=a, b, c ;
\end{array}
$$

To inject maximum active power $(\mathrm{P})$ from the MMC to the grid, the current injected by the MMC must be in phase with the fundamental component of the grid voltage.

\section{CASE Studies Simulation AND EVAluation}

The MMC with eight cells per leg is simulated to evaluate the performance of the proposed model. Each PV string, integrated into SM of MMC through a buck converter, has eight series-connected PV modules. The overall STC power rating of PV generators is $45.85 \mathrm{~kW}$ and that of each PV string is $1.91 \mathrm{~kW}$. The specifications of a PV module at STC and buck converter parameters are tabulated in Table I, whereas parameters of backup module and grid-connected MMC are given in Table II and III, respectively. The overall storage capacity of split batteries is $6.6 \mathrm{Ah} * 4 * 2 * 3=158.4 \mathrm{Ah}$.

\section{A. Case Study I}

Severe partial shading occurs from $\mathrm{t}=0 \mathrm{~s}$ to $0.4 \mathrm{~s}$, during this period only first seven PV strings of phase-A operate at $70 \%$ irradiance which lead to almost $4000 \mathrm{~W}$ capacity loss from phase-A but all other PV strings operate at STC during whole simulation. During this period, no BESS is activated as PV power $\left(\mathrm{P}_{\mathrm{PV}}\right)$ is equal to grid power demand. At $\mathrm{t}=0.4 \mathrm{~s}$ the worst-case scenario occurs i.e. there is a step decrease in PV power due to further $30 \%$ decrease in irradiance of first seven PV strings of phase-A, and at the same instant a step increase in grid power demand occurs.

The control system activates the SM-integrated BESS which meets the capacity loss plus step increase in the grid power demand. At $\mathrm{t}=0.6 \mathrm{~s}$, third test case starts which evaluates the behavior of the system with step increase in both $\mathrm{P}_{\mathrm{PV}}$ and grid power demand. Since the increase in grid power demand is higher than the increase in $\mathrm{P}_{\mathrm{PV}}$, so the control system updates the power references of BESS and again the mismatch power is supplied by BESS. Fig. 4 visualizes these test cases.

Because of the improvement in the introduced control scheme, output currents shown in Fig. 5 are balanced and have very low total harmonic distortion even under severe partial shading as shown in Fig. 6. Fig. 7 depicts the three phase AC voltage. Fig. 8 shows that circulating currents are quite close to zero even during step changes in irradiance and grid power demand. Moreover, DC-link voltage as well as SM capacitor voltages are regulated at their respective references.

It has also noti ced that SM integration of distributed PV generators directly effects the SM capacitor voltage and leads to increased harmonics. But an improvement in P\&O MPPT

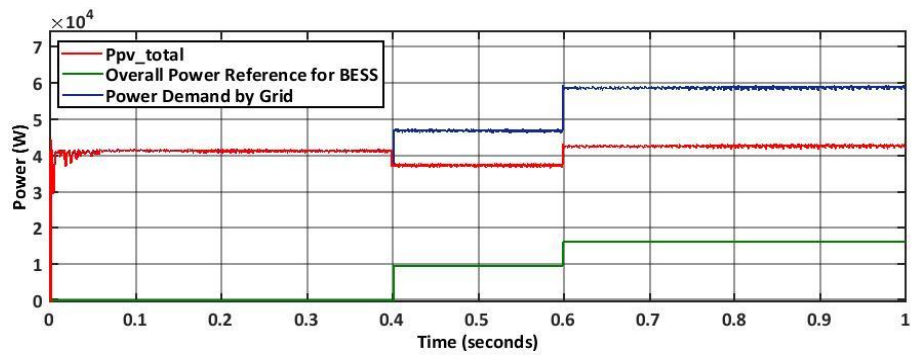

Fig. 4. Grid power demand curve, $P_{P V}$ total, and overall power reference for BESS.
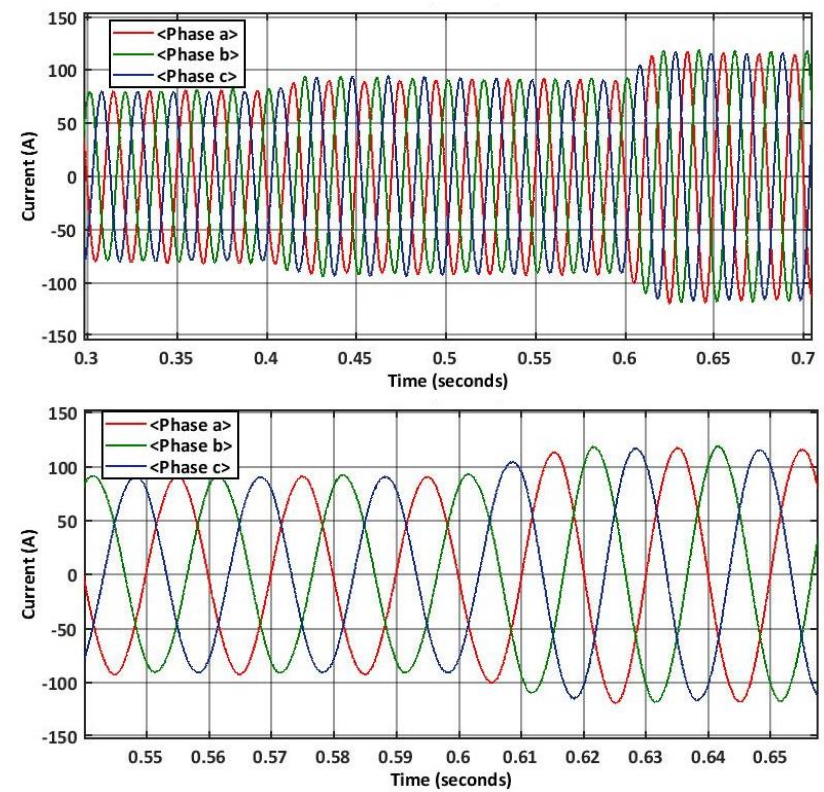

Fig. 5. Output phase currents of conversion unit

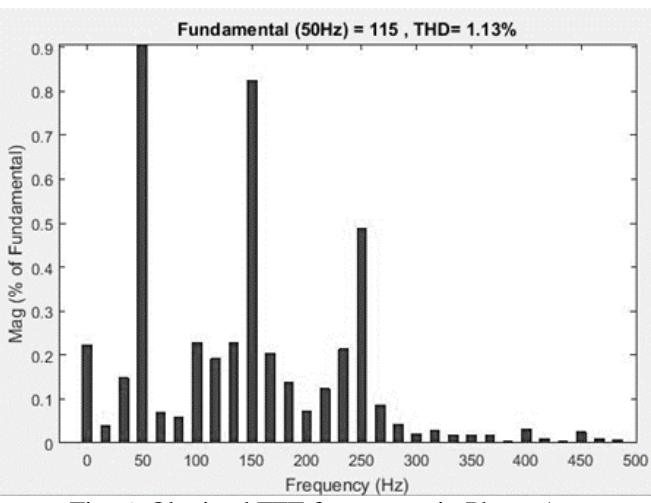

Fig. 6. Obtained FFT for current in Phase-A. 
not only improves the convergence and efficiency but also reduces the adverse effects conventional $\mathrm{P} \& \mathrm{O}$ technique. The SM capacitor voltage as shown in Fig. 9. P\&O MPPT with smaller step size and proper upper and lower limits for duty ratio causes less higher order harmonics in the SM capacitor voltage.

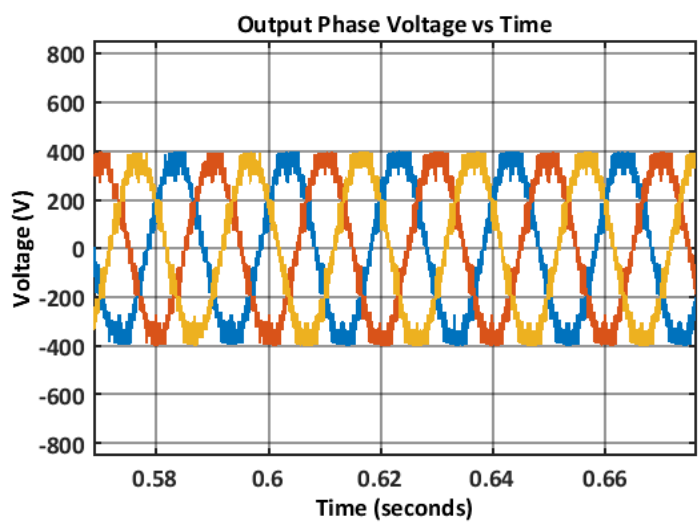

Fig. 7. Simulated waveform of output phase voltages.

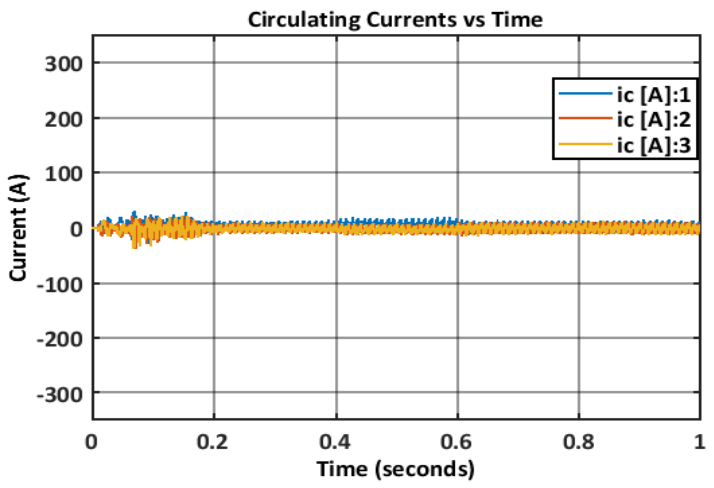

Fig. 8. Circulating currents under abrupt power generation and demand changes.
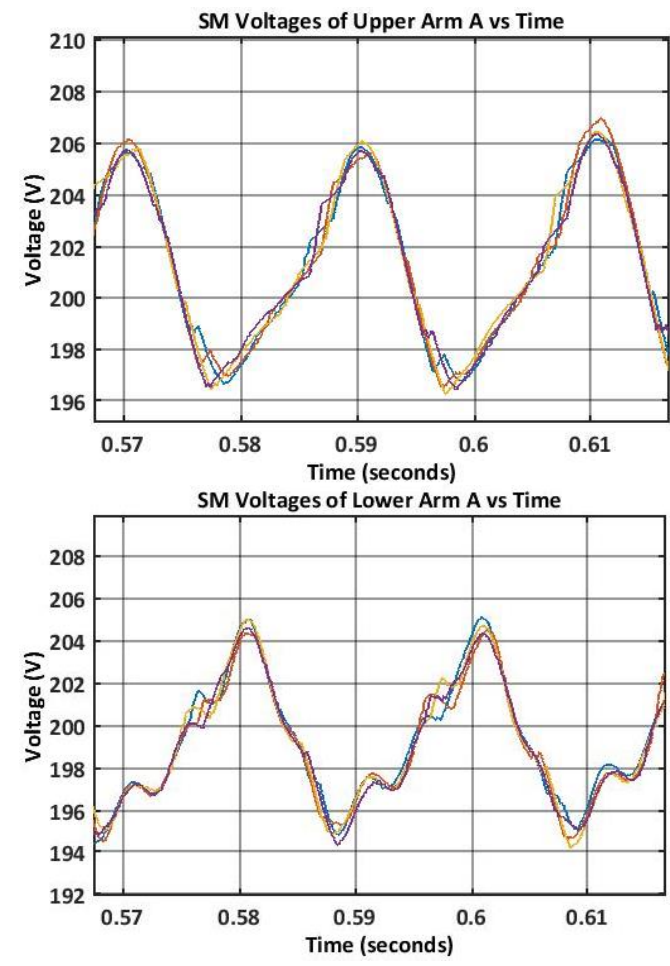

Fig. 9. SM capacitor voltage of upper arm of phase-A with enhancement of P\&O MPPT while lower arm PV generators operate without this enhancement.
Without this improvement, presence of higher (especially $4^{\text {th }}$ ) order harmonics in the SM capacitor voltage of lower arm (i.e. having conventional P\&O MPPT) is observed. With P\&O MPPT improvement, the upper arm SM capacitors have almost same level of voltage fluctuations but considerably low higher order harmonic distortions, as shown in Fig. 9.

\section{B. Case Study II}

This case study investigates the ramp and step changes in the grid power demand, as well as the scenario when overall PV power generation $\left(\mathrm{P}_{\mathrm{PV}}\right)$ becomes higher than the grid demand. Higher power production and less consumption may lead to voltage rise and stability issues at PCC but the control system of flexible energy conversion activates the SMintegrated BESS system instantly and provides the BESS controller with a new reference which leads to charging of split batteries. Storage of electrical energy, into split batteries, provides a backup for higher power demand situations and also improves the stability of PCC.

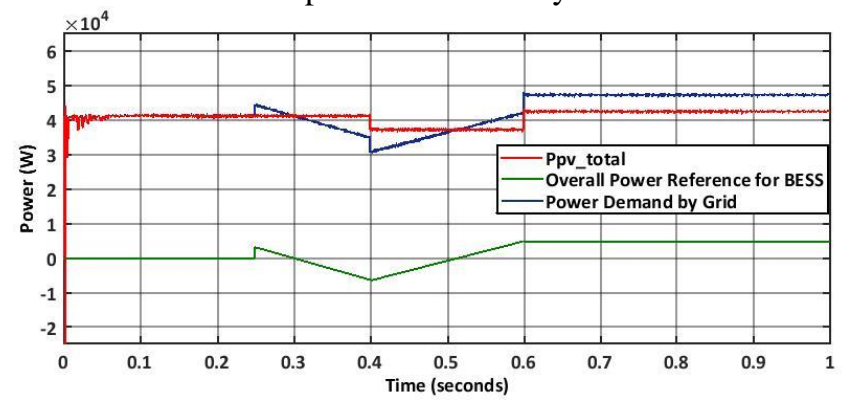

Fig. 10. Grid power demand curve, $\mathrm{P}_{\mathrm{PV}}$ total, and overall power reference for BESS.

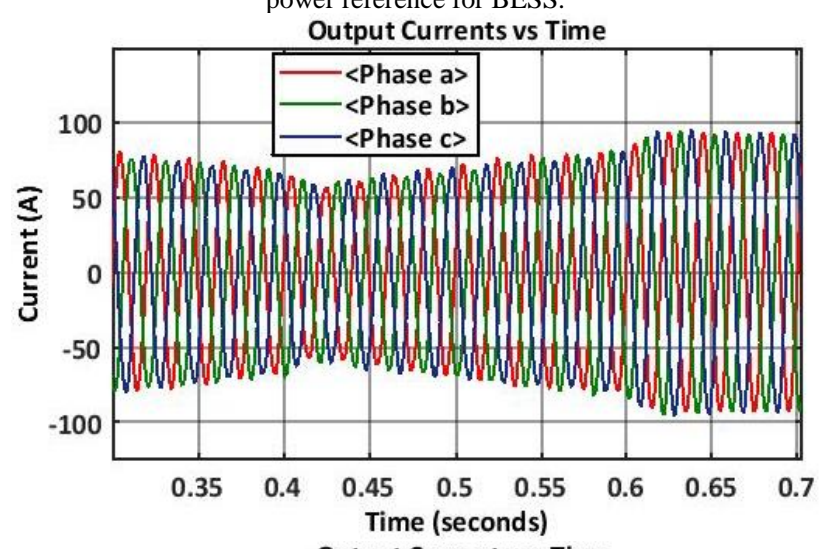

Output Currents vs Time

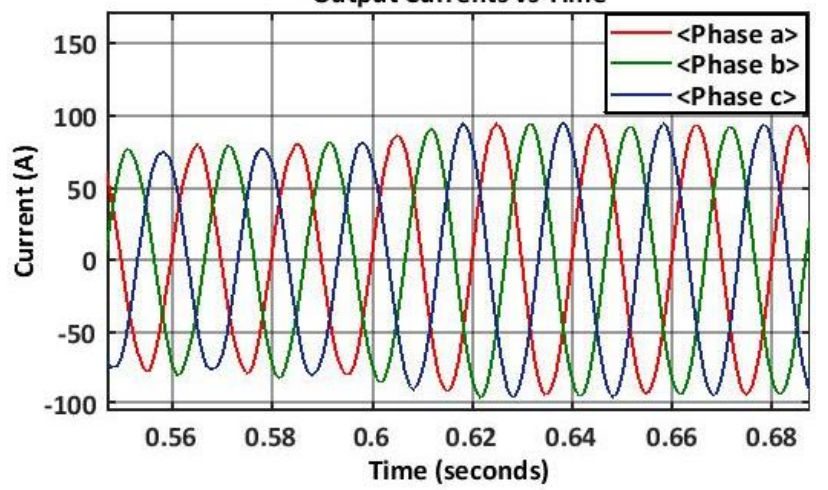

Fig. 11. Three-phase output currents versus time.

Severe partial shading occurs from $\mathrm{t}=0 \mathrm{~s}$ to $0.4 \mathrm{~s}$, during this period only first seven PV strings of phase-A operate at $70 \%$ irradiance which lead to almost $4000 \mathrm{~W}$ capacity loss from 
nominal power of phase-A, but all other PV strings operate at STC during whole simulation. Between $\mathrm{t}=0 \mathrm{~s}$ to $0.25 \mathrm{~s}$, no BESS is activated as $\mathrm{PV}$ power $\left(\mathrm{P}_{\mathrm{PV}}\right)$ is equal to grid power demand i.e. $41110 \mathrm{~W}$. At $\mathrm{t}=0.25 \mathrm{~s}$, there is an abrupt increase in power demand by the grid of around $3333 \mathrm{~W}$ but instantly this rise in power demand starts decreasing linearly and reaches to $35000 \mathrm{~kW}$ at $\mathrm{t}=0.4 \mathrm{~s}$. At $\mathrm{t}=0.3 \mathrm{~s}$, the grid power demand becomes lower than the PV power generation. The autonomous control system instantly activates the BESS and provide it with the charging signal so the split batteries starts charging with the surplus power. At $\mathrm{t}=0.4 \mathrm{~s}$, a sudden decrease in grid power demand of approximately 4000W occurs. This sudden drop in power demand is compensated by reduction of $\mathrm{P}_{\mathrm{PV}}$ value; as at $\mathrm{t}=0.4 \mathrm{~s}$, a step decrease in PV power due to $30 \%$ decrease in irradiance of first seven PV strings of phase-A occurs. After $\mathrm{t}=0.4 \mathrm{~s}$, the grid power demand instantly starts increasing and reaches to $42.2 \mathrm{~kW}$ at $\mathrm{t}=0.6 \mathrm{~s}$. During this rise, power demand again intersects the $P_{\mathrm{PV}}$ curve at $\mathrm{t}=0.515 \mathrm{~s}$ which leads to change the mode of BESS from charging to discharging.

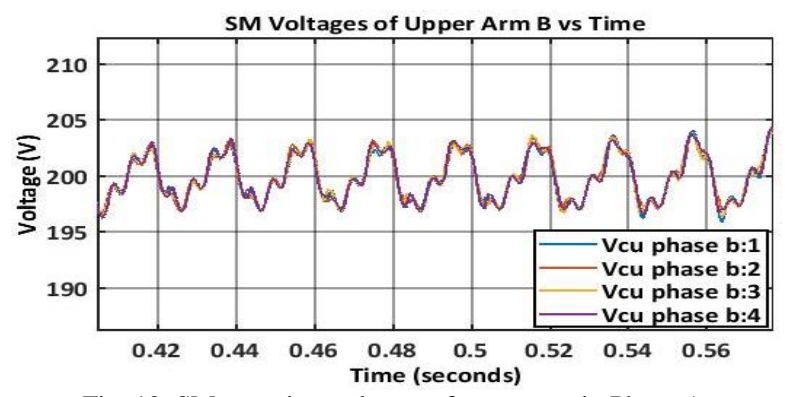

Fig. 12. SM capacitor voltages of upper arm in Phase-A.

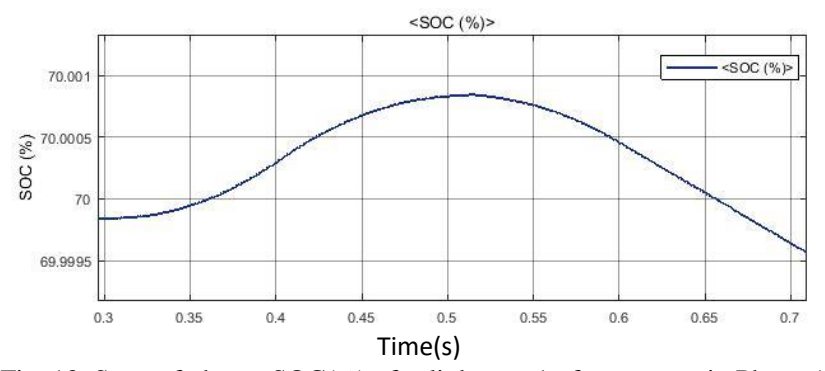

Fig. 13. State-of-charge SOC $(\%)$ of split battery1 of upper arm in Phase-A.

At $\mathrm{t}=0.6 \mathrm{~s}$, the solar irradiance of first seven PV strings of phase-A increases from $40 \%$ to $80 \%$ so $\mathrm{P}_{\mathrm{PV}}$ becomes $42.45 \mathrm{~kW}$ and remains here until end of simulation. At $\mathrm{t}=0.6 \mathrm{~s}$, a step increase in grid power demand occurs which makes the mismatch equal to $5.25 \mathrm{~kW}$, the autonomous control system activates the BESS which starts discharging and make this mismatch equal to zero without any noticeable delay. Fig. 10 visualizes the above given scenarios.

Fig. 11 shows the three phase AC currents, which are being injected from the MMC-based PV-battery hyrbid system to the grid. Fig. 12 shows the SM capacitor voltage of upper arm of phase-A, which are balanced even under charging and discharging of split batteries and variable grid power demand. Fig. 13 shows the percentage state of charge (SOC $(\%)$ ) vs time which conforms with the the discussion above.

\section{CONCLUSION}

This paper addresses the issues of the intermittent PV power and resolves the problem of partial shading, which is a major challenge in centralized PV systems. Because of the integration of BESS, the stability of point of common coupling (PCC) is improved. Peak-shaving feature can also be realized to meet the variable PCC power demand, and less or no contribution from the grid is required. The designed control system injects balanced three-phase currents in to the grid, even when there are large differences between powers of internal arms or phases, while keeping the circulating current in its low level. This proposal brings the distributed and modular structure of the PV-battery hybrid system that is highly reliable, efficient and produces very less THD.

The results validate that proposed topology is a complete solution for grid-connected PV systems. Moreover, it could be used in weak grids or micro-grids, and for solar Electric Vehicles (EVs) to adopt the Vehicle-to-Grid (V2G) technology.

\section{REFERENCES}

[1] H. Nademi, L. Norum, Sigurd Wersland, "An Accurate MPPT Scheme for Photovoltaic Modular-Based Conversion Units: A Robust Sensorless Predictive Approach," in Proc. IEEE 18th COMPEL 2017, Stanford, USA, July 9-12, 2017, pp. 1-6.

[2] H. Nademi, A. Das, R. Burgos and L. Norum "A New Circuit Performance of Modular Multilevel Inverter Suitable for Photovoltaic Conversion Plants," IEEE J. Emerg. Sel. Topics Power Electron., vol. 4, no. 2, pp. 393-404, June 2016.

[3] M. Vasiladiotis and A. Rufer, "Analysis and Control of Modular Multilevel Converters With Integrated Battery Energy Storage," IEEE Trans. Power Electron., vol. 30, no. 1, pp. 163-175, Jan. 2015.

[4] ABB Inc., "DynaPeaQ ${ }^{\circledR}$ Energy Storage System- A UK first," https://library.e.abb.com/public/5c6dc4bd73860eb7c125793a0043a0e9/A 02-0224\%20E\%20LR.pdf

[5] G. Konstantinou, J. Pou, D. Pagano and S. Ceballos, "A Hybrid Modular Multilevel Converter with Partial Embedded Energy Storage," Energies, vol. 9, no. 12, Nov. 2016.

[6] T. Soong and P. W. Lehn, "Evaluation of Emerging Modular Multilevel Converters for BESS Applications," IEEE Trans. Power Del., vol. 29, no. 5, pp. 2086 - 2094, Oct. 2014.

[7] F. Guo, Y. Ye and R. Sharma, "A modular multilevel converter based battery-ultracapacitor hybrid energy storage system for photovoltaic applications," in Proc. Clemson University Power Systems Conference (PSC), Clemson, USA, March 2015, pp. 1-6.

[8] I. Trintis, S. Munk-Nielsen and R. Teodorescu, "A new modular multilevel converter with integrated energy storage," in Proc. IEEE 37th IECON 2011, Melbourne, Australia, Nov. 2011, pp. 1075-1080.

[9] H. Kim, B. Parkhideh, T. D. Bongers and H. Gao, "Reconfigurable Solar Converter: A Single-Stage Power Conversion PV-Battery System," IEEE Trans. Power Electron., vol. 28, no. 8, pp. 3788 - 3797, Aug. 2013.

[10] T. Soong and P. W. Lehn, "Assessment of Fault Tolerance in Modular Multilevel Converters With Integrated Energy Storage," IEEE Trans. Power Electron., vol. 31, no. 6, pp. 4085-4095, June 2016.

[11] Y.-X. Wang, F.-F. Qin, and Y.-B. Kim, "Bidirectional DC-DC converter design and implementation for lithium-ion battery application," in Proc. IEEE Power and Energy Engineering Conference (APPEEC 2014), Dec. 2014, pp. 1-5.

[12] O. C. Onar, and A. Khaligh, "A Novel Integrated Magnetic Structure Based DC/DC Converter for Hybrid Battery/Ultracapacitor Energy Storage Systems," IEEE Trans. Smart Grid, vol. 3, no. 1, pp. 296-307, Mar. 2012. 